\title{
Cause of Paraparesia in Childhood: Spinal Chondrosarcoma
}

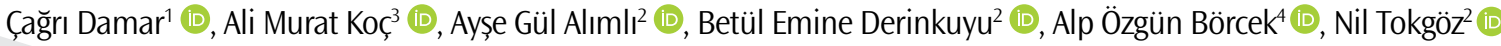

\begin{abstract}
Chondrosarcomas are common primary malignant bone tumors that are mostly seen in adulthood. Spinal involvement is uncommon among all sites of involvement of the tumor; spinal chondrosarcoma in childhood is particularly rare. Here we present the imaging findings of a spinal lowgrade chondrosarcoma in a 7-year-old boy, which was later surgically excised and pathologically proven. Differentiation of chondrosarcoma from other spinal tumors may be difficult in cases of indeterminate tumoral origin in spinal compartments, and it may require a multi-modal imaging approach. Demonstration of dural interface is very important for an accurate diagnosis. Also, changes in the neural foraminal width and vertebral architecture and the integrity of the spinal cord are important criteria for differential diagnosis.
\end{abstract}

Keywords: Spina, chondrosarcoma, childhood, extramedullary tumor, dural interface

ORCID IDs of all authors: C..D. 0000-0001-72081290; A.M.K. 0000-0001-6824-4990; A.G.A. 00000002-4339-4236; B.E.D. 0000-0003-2434-1398; A.Ö.B. 0000-0002-6222-382X; N.T. 0000-00032812-1528.

'Department of Radiology, Gaziantep Maternity and Childrens Hospital, Gaziantep, Türkiye ${ }^{2}$ Department of Radiology, Izmir Bozyaka Training and Research Hospital, İzmir, Türkiye ${ }^{3}$ Department of Radiology, Gazi University School of Medicine, Ankara, Türkiye ${ }^{4}$ Department of Neurochirurgy, Gazi University School of Medicine, Ankara, Türkiye

Address for Correspondence:

Çă̆rı Damar

E-mail: cagridamar@hotmail.com

Received: 08.08 .2016

Accepted: 19.11.2017

(c) Copyright 2018 by Available online at istanbulmedicaljournal.org

\section{Introduction}

Spinal chondrosarcomas are uncommon tumors of childhood. It requires multimodality imaging techniques for differentiation from other tumors. Low-grade chondrosarcomas rarely mimic nerve sheet tumors with the compressive effects on the surrounding structures without distinct destruction (1). Herein we report a pediatric case of this tumor.

\section{Case Report}

A 7-year-old boy was admitted to department of pediatrics with dorsal pain and weakness of lower extremities that lasted for a month without any history of trauma.

There was an extramedullar mass in the spinal canal at the Th1 and Th2 levels, indicated by the magnetic resonance imaging (MRI) scans. The mass was centrally hyperintense on T2-weighted (T2w) imagesbesides enhancing peripherally and heterogeneously on T1-weighted (T1w) images after the administration of gadolinium. The spinal cord was compressed, and the spinal canal was enlarged together with the right neural foramen. Hyperintense signal changes which seemed to be present at the level of cerebrospinal fluid intensity were also noticed around the mass (Figure 1). Posterior compressive scalloping of the Th1 vertebral body and other findings mentioned above were suggesting an intradural-extramedullar mass, possibly a nerve sheet tumor.

Because of the complex anatomic location and for further evaluation of the lesion, a computed tomography (CT) scan was performed. The CT scan of the spine revealed an expansile, peripherally calcified lobulated mass in the spinal canal with mild central hypodensity (compared to the density of muscle, $20 \mathrm{HU}$ ) that was extending into the right neural foramen at the Th1-Th2 level (Figure 2a). There was no distinct destruction of adjacent bony structures, with the exception of the right-superior articular process of the Th2 vertebra. It was concluded that the mass was an extradural exophytic tumor arising from this vertebral element (Figure 2b). We re-evaluated the MRI scans for this challenging appearance and confirmed the presence of a dural interface between the tumor and spinal cord (Figure 3).

In surgery, to reveal the mass and determine its relation with spine and spinal cord, first, the T1 total and T2 right hemi-laminectomy was performed. After en-block resection, the mass was diagnosed as Grade 1 chondrosarcoma after pathological examination. The patient was discharged, and neither residue nor recurrence was found on follow up radiologic examinations (Figure 4). Informed consent was obtained from the patient's parents for publication. 

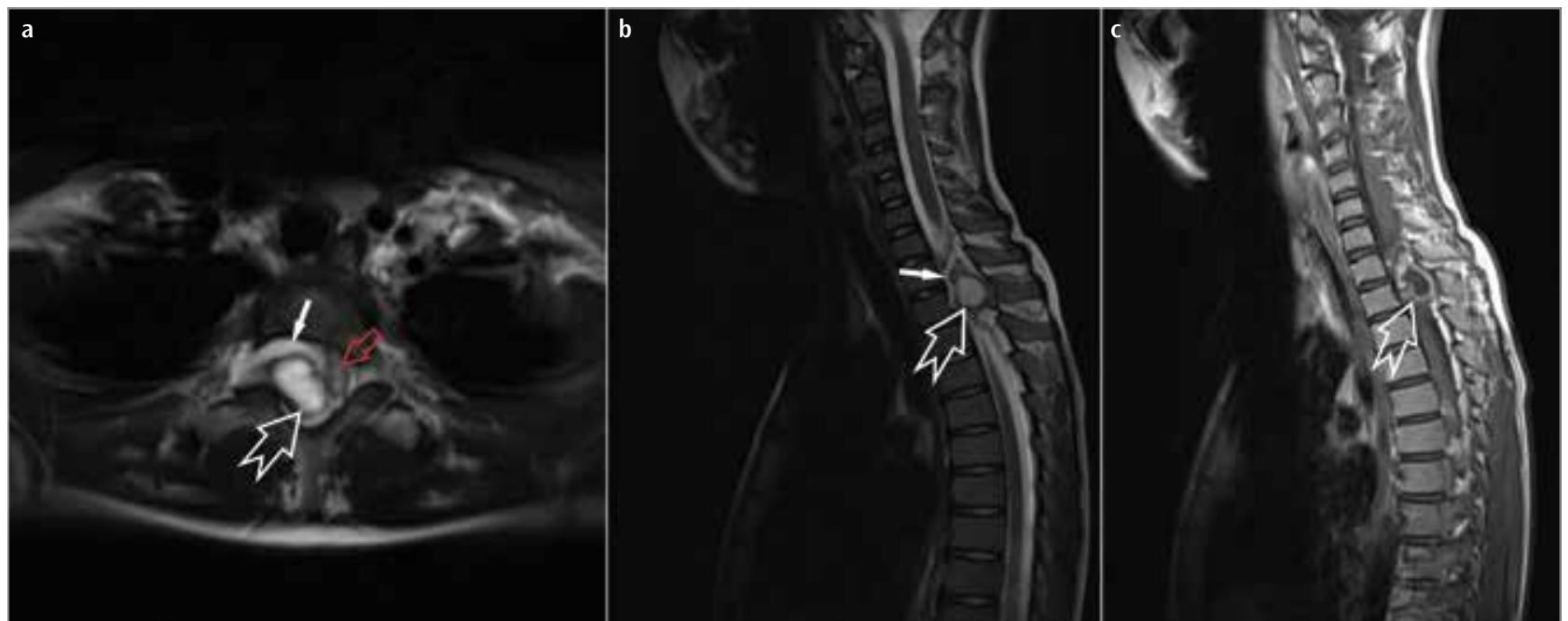

Figure 1. a-c. Axial (a) and sagittal (b) MR images demonstrate an intraspinal extramedullary lobulated cystic mass extending into the right neural foramen. Note that there is some hyperintense material around the mass on T2-weighted images as cerebrospinal fluid intensity (white solid arrows). The spinal cord was compressed and anterolaterally displaced left in the spinal canal (red arrow). The postcontrast T1-weighted sagittal image (c) shows some peripheral enhancement in the mass.
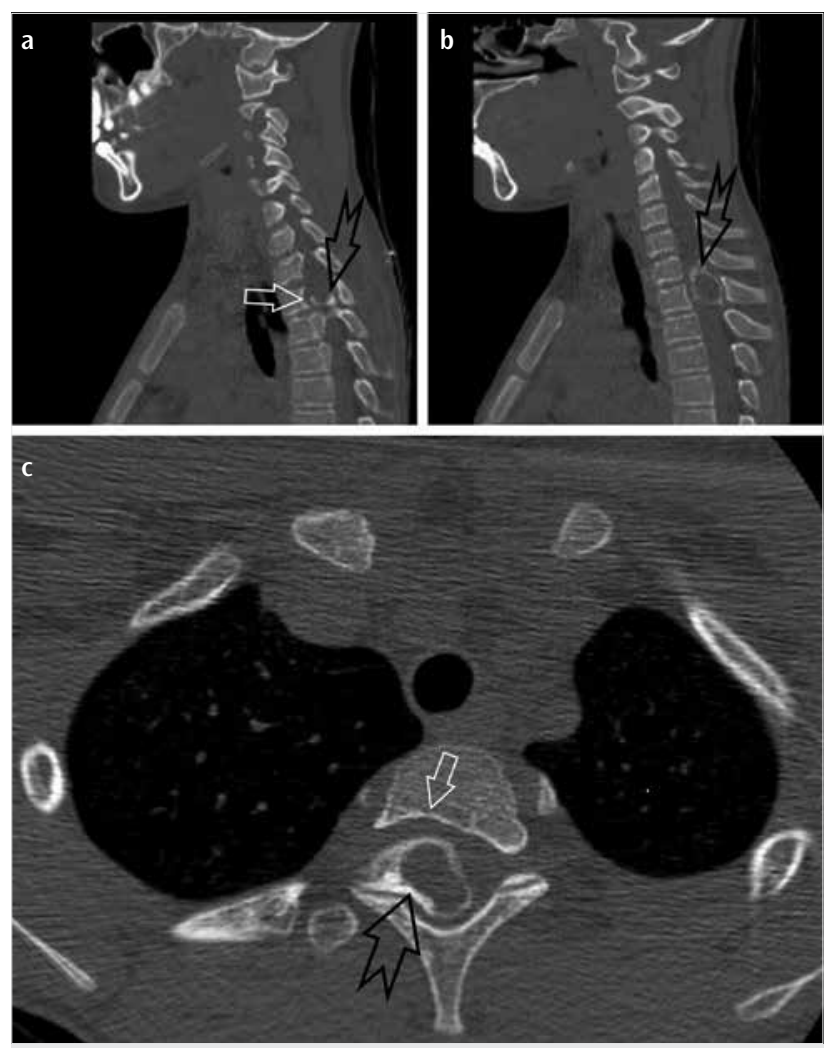

Resim 2. a-c. Sagittal reformatted (a, b) and axial (c) CT images disclose a peripherally calcified lobulated mass in the spinal canal originating from the right-superior articular process of the Th2 vertebra (chewron arrows). The white arrows (a, c) reveal posterior scalloping of the Th1-vertebral body. The spinal canal and the right neural foramen are enlarged at the level of Th1-Th2.

\section{Discussion}

Chondrosarcomas are the third most common nonhematological bone tumors, following osteosarcomas and Ewing's sarcoma that account for about $25 \%$ of all primary malignant bone tumors (2, $3)$. They usually present between the $4^{\text {th }}$ and the $7^{\text {th }}$ decade of life, with a male predominancy $(3,4)$.

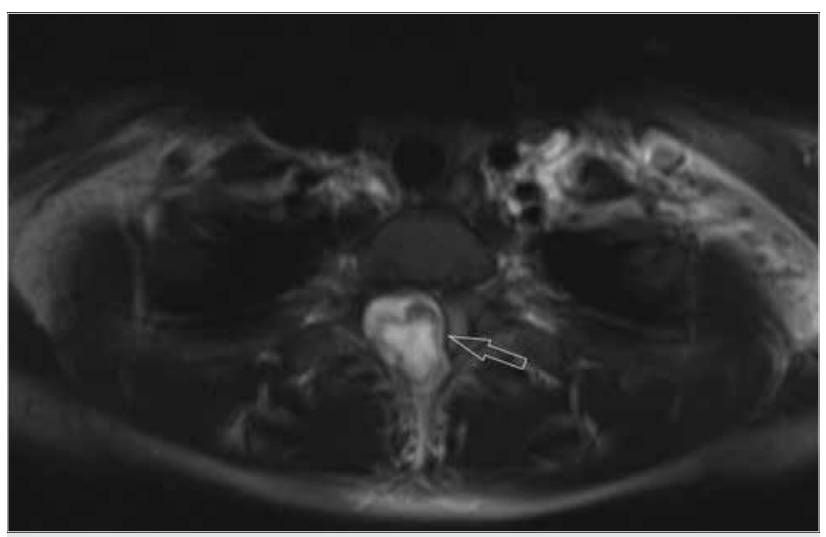

Resim 3. The axial T2-weighted image shows thin hypointense dural interface between the tumor and the spinal cord (open arrow).

These neoplasms can arise primary (de novo) (85\%) or secondary (15\%) from a preexisting lesion with sarcomatous degeneration. Secondary chondrosarcomas, which may arise from enchondromas or osteochondromas, are usually low grade and have a better prognosis. Patients with Ollier disease, Mafucci syndrome, or hereditary multiple exostosis are at a higher risk of chondrosarcoma than those with solitary cartilaginous lesions (2).

Chondrosarcomas are generally low-grade, slow-growing tumors $(2,5,6)$. The hip and shoulder joints are main sites of involvement; the iliac bone, bones around the shoulder, and proximal ends of humerus and femur are the most effected bones $(4,5)$. Spinal involvement is seen in approximately $10 \%$ of patients (2, 6). The thoracic region is the most common site of involvement in spine, with a predilection of posterior vertebral elements (13). Primary chondrosarcomas arise mainly from vertebral bodies; on the other hand, main locations of the secondary types are the posterior elements (7). Our case did not have any known prior lesions, but the tumor had involved the articular facet unlike most of the primary chondrosarcomas originating from the vertebral body. 

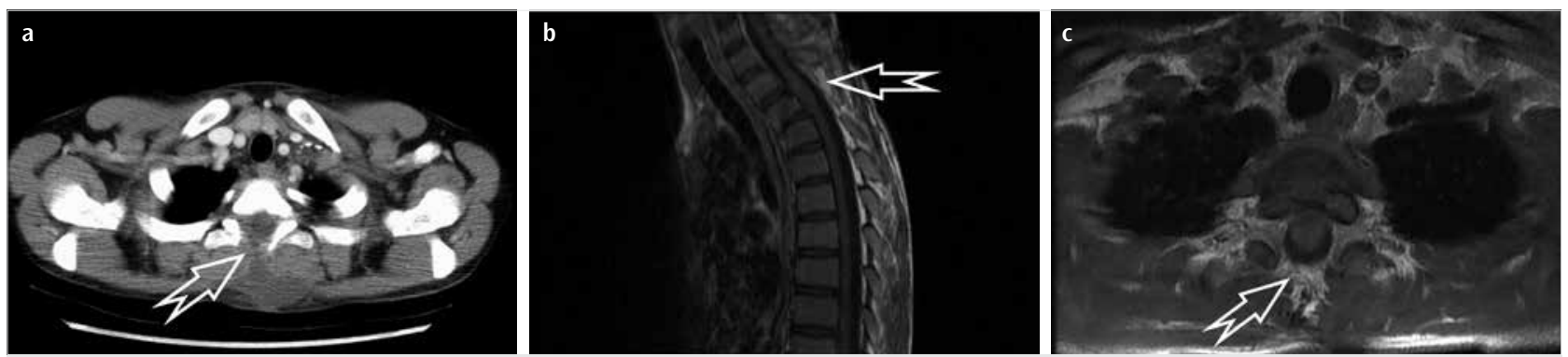

Figure 4. a-c. Early postoperative axial CT image (a) shows that there is no residue of the mass. Postoperative followup images (1 year later); axial (b) and sagittal (c) postcontrast T1-weighted MR images reveal that there is no pathologic signal intensity or enhancement compatible with recurrence. Note that there are laminectomy defects in the posterior elements of the Th1 and Th2 vertebrae. Posterior scalloping of the Th1 vertebral body improved.

Less than $10 \%$ of chondrosarcomas occur in childhood (4). They usually present with slow-growing night pain and sometimes a palpable mass. Occasionally, neurologic symptoms appear because of spinal cord compression from chondrosarcomas, like in the current case $(2,3,6)$.

Chondrosarcomas can be defined as central (intramedullary), peripheral, and juxtacortical (periosteal) on the basis of their location in the bone $(2,3,8)$. Because of its pathologic characteristics, chondrosarcomas have been classified into the following conventional and variant subtypes: clear cell, myxoid, mesenchymal, and dedifferentiated. The grades of these variant types are variable between low to high grade $(2,5,8)$. It is known that spinal chondrosarcomas are extradural tumors, but there are some reports about intradural lesions regarding these variant subtypes (9-11). The grading system is based on tumor cellularity, and there are three main histologic grades $(2,7,8)$. Low-grade, centrally (intramedullary) located conventional type is the most common, and it represents up to $90 \%$ of all chondrosarcomas (24 , 9). Our patient had a low-grade juxtacortical-exophytic located tumor, which is not very aggressive, so it could be successfully resected en-bloc.

Chemotherapy and radiotherapy have not been demonstrated as successful treatment options. The pelvis, sacrum, or spine are difficult locations for en-bloc resection, which is the sole therapeutic option. Hence, the life expectancy of patients with these tumor locations is lower than others. Although surgery is the best option, the recurrence rates are quite high after tumor debulking without safe surgical margins $(1,2,4,12,13)$.

These cartilaginous tumors produce a chondroid matrix (2-5). Radiological findings correlate well with histological grades $(5,8,12)$. Low-grade lesions have dense spicules of calcification, whereas high-grade lesions have amorphous areas of calcification and concentric growth of this soft tissue component (7). Nonmineralized central hypodensity reflects the high water content of hyaline cartilage on CT images. MRI characteristics of the tumor are iso- to hypointense on T1w and heterogenous on T2w images. Peripheral and lobulated rim enhancement is seen on postcontrast T1w images. Mineralized areas are responsible for hypointense signals, contrary to predominant nonmineralized areas which are hyperintense because of high water content of matrices on T2w images (8).

Findings may vary from lysis that interferes with enchondromas to moth-eaten destruction and the discriminative "rings-and-arcs" type of tumoral calcification that represents enchondral calcification $(2-4,8,12)$. The involvement of axial skeleton; peripheral, nodular, and septal enhancement; peritumoral edema and endosteal scalloping of $>2 / 3^{\text {rd }}$ of cortical thickness are all in favor of chondrosarcomas rather than enchondroma (4).

Chondrosarcomas rarely present as a dumbbell-shaped mass causing neural foraminal widening, as in our present report $(5,11,14$, 15). Peripheral calcification with central nonmineralized areas and peripheral and heterogenous enhancement supported the diagnosis of chondrosarcoma, which was pathologically made after surgical excision in our patient.

\section{Conclusion}

Spinal low-grade chondrosarcomas in childhood may mimic the imaging findings of nerve sheet tumors in terms of spinal cord compression, bony scalloping, and neural foraminal enlargement. It is difficult to detect the dural interface, but once it is observed, it definitely helps initial diagnosis.

Informed Consent: Informed consent was obtained from parents of the patient who participated in this study.

Peer-review: Externally peer-reviewed.

Author Contributions: Concept - Ç.D., A.M.K.; Design - C..D., A.M.K.; Supervision - N.T., A.Ö.B.; Resource - A.G.A., B.D.; Materials - A.G.A., B.D.; Analysis and/or Interpretation - N.T., A.Ö.B.; Literature Search - A.G.A., B.D.; Writing - Ç.D., A.M.K.; Critical Reviews - N.T., A.Ö.B.

Conflict of Interest: The authors have no conflicts of interest to declare.

Financial Disclosure: The authors declared that this study has received no financial support.

\section{References}

1. Prevedello DM, Cordeiro JG, Koerbel A, Ditzel LF, Araújo JC. Management of primary spinal chondrosarcoma: report of two cases causing cord compression. Arq Neuropsiquiatr 2004; 62: 875-8. [CrossRef]

2. Katonis P, Alpantaki K, Michail K, Lianoudakis S, Christoforakis Z, Tzanakakis G, et al. Spinal chondrosarcoma: a review. Sarcoma 2011; 2011: 378957. [CrossRef]

3. Wald, JT. Imaging of spine neoplasm. Radiol Clin North Am 2012; 50: 749-76. [CrossRef]

4. Mosier SM, Patel T, Strenge K, Mosier AD. Chondrosarcoma in childhood: the radiologic and clinical conundrum. J Radiol Case Rep 2012; 6: 32-42. [CrossRef] 
5. Liu G, Wu G, Ghimire P, Pang H, Zhang Z. Primary spinal chondrosarcoma: radiological manifestations with histopathological correlation in eight patients and literature review. Clin Imaging 2013; 37: 124-33. [CrossRef]

6. Boriani S, De lure F, Bandiera S, Campanacci L, Biagini R, Di Fiore M, et al. Chondrosarcoma of the Mobile Spine; Report on 22 Cases. Spine (Phila Pa 1976) 2000; 25: 804-12. [CrossRef]

7. Stuckey RM, Marco RA. Chondrosarcoma of the mobile spine and sacrum. Sarcoma 2011; 2011: 274281.

8. Murphey MD, Walker EA, Wilson AJ, Kransdorf MJ, Temple HT, Gannon FH. From the Archives of AFIP: Imaging of Primary Chondrosarcoma: Radiologic-Pathologic Correlation. Radiographics 2003; 23: 1245-78. [CrossRef]

9. Kupeli S, Varan A, Gedikoğlu G, Büyükpamukçu M. Sacral mesenchymal chondrosarcoma in childhood: a case report and review of the literature. Pediatr Hematol Oncol 2010; 27: 564-73. [CrossRef]

10. Kotil K, Bilge T, Olagac V. Primary intradural myxoid chondrosarcoma: a case report and review in the literature. J Neurooncol 2005; 75: 169-72. [CrossRef]
11. Bae GS, Choi SW, Youm JY, Kim SH. Primary spinal dumbbell-shaped mesenchymal chondrosarcoma located intradurally and extradurally. J Korean Neurosurg Soc 2011; 50: 468-71. [CrossRef]

12. Orguc $\mathrm{S}$, Arkun R. Primary tumors of the spine. Semin Musculoskelet Radiol 2014; 18: 280-99. [CrossRef]

13. Ozturk AK, Gokaslan ZL, Wolinsky JP. Surgical treatment of sarcomas of the spine. Curr Treat Options Oncol 2014; 15: 482-92. [CrossRef]

14. Yünten N, Calli C, Zileli M, Ustün EE, Sener RN. Chondrosarcoma causing cervical neural foramen widening. Eur Radiol 1997; 7: 1028-30. [CrossRef]

15. Zibis AH, Markonis A, Karantanas AH. Unusual causes of spinal foraminal widening. Eur Radiol 2000; 10: 144-8. [CrossRef]

Cite this article as: Damar C, Koç AM, Alımlı AG, Derinkuyu BE, Börcek AÖ, Tokgöz N. Cause of Paraparesia in Childhood: Spinal Chondrosarcoma. İstanbul Med J 2018; 19: 176-9. 